\title{
A BENCHMARK MODEL FOR INTERNAL ASSESSMENT OF INDUSTRY USING FUZZY TOPSIS APPROACH
}

\author{
Bhupender Singh ${ }^{1}$, Sandeep Grover ${ }^{2}$ and Vikram Singh ${ }^{3}$ \\ ${ }^{1,2,3}$ Department of Mechanical Engineering, YMCA University, Faridabad, India
}

\begin{abstract}
Internal assessment is one of the most important factor of an industry, needs appropriate improvement planning between the departments with development of Benchmark model among them. The proposed study applies Fuzzy Technique for Order Preference by Similarity to Ideal Solution to rank different alternatives. The preliminary results indicate that the proposed model is capable of determining appropriate competition between departments which are Human Resource, Finance, Production, Quality Assurance. To remove the subjectivity, the linguistic data about the attributes is converted into a crisp score by using fuzzy numbers and then the different alternatives are evaluated based on attributes by TOPSIS approach to find the best alternative according to the industry's requirement. Thus the endeavor has been made by the authors to give a simple model for the evaluation of internal assessment of an industry.
\end{abstract}

\section{KEYWORDS}

Benchmarking, MADM, Assessment, Ranking, Industry

\section{INTRODUCTION}

The essence of benchmarking is the process of identifying the highest standards of excellence for products, services and then make the improvements required to reach those standards, commonly called "best practices". Benchmarking is recognized as "an essential tool for continuous improvement of quality" (Dattakumar \& Jagadeesh 2003). Benchmarking is an important business practice priority and well defined tool for improving the weakness through improvement processes in which a company measures its performance against market leaders, finds how market leaders have achieved their performance levels and prudently uses this knowledge to improve its own performance (Saunders, Mann \& Smith 2007).Benchmarking has been introduced by practitioners for improving their corporate competitive advantage. It has also been effectively used to reengineer business improvement programmes rely on effective development, integration and analysis of measurement data.

In the current society, with an increasing trend and complexity of information, the primary focus of industrial enterprises is to have continuous improvement. Since there is a close competition in the manufacturing industries and the market is highly competitive in this industry. Benchmarking is the most popularly adopted by industries to understand how well they are performing relative to their competitors. It is also used to identify what management practices are worthwhile to apply in own firm in order to achieve desired performance goals. Benchmarking has been defined 
as the search for industry best practices that lead to superior performance (Camp 1989). In the process of best practice benchmarking, management identifies the best firms in their industry or in another industry where similar processes exist, and compares the results and processes of those studied to one's own results and processes. In this way, they learn how well the targets perform and more importantly the business processes that explain why these firms are successful.

In this study addition to industry analysis, it is trying to design a model for its department using Multi Criteria Decision Making method and fuzzy approach. This study is intended not only to increase competitiveness by providing the above model, but also to state that where departments lies for standardization. Since industries contains intangibility, inseparability and heterogeneity it makes people more difficult to measure quality.Since the evaluation is resulted from evaluator's view of linguistic variables, it must be conducted in an uncertainty,fuzzy environment. In order to overcome the issue, fuzzy set theory will be used into the measurement of performance.Fuzzy set theory aids in measuring the ambiguity of concepts that are associated with human being's subjective judgment. Nowadays, the fuzzy set theory has been applied to many fields of management science, like decision making (Chen, \& Tzeng, 2007; Huang, Chiang, 2008; Liu \& Lai, 2009) however, it is scarcely used in the field of service quality.

We propose a novel two-dimensional approach that determines the deferrable strategy with the most value by maximizing the real option values while minimizing the risks associated with each alternative strategy. Also, there is a need for an effective tool in identifying and prioritizing relevant criteria to develop a systematic quality measurement process. The approach should also develop consensus decision making because MADM is a practical tool for selection and ranking of a number of alternatives and its applications are numerous. The high flexibility of this concept is able to accommodate further extension to make better choices in various situations. It is not uncommon for certain groups to constantly make complex decisions within organizations. However for using any MADM technique it is usually assumed that the decision information is provided in advance by a group of team. TOPSIS has been deemed one of the major decision making techniques within the manufacturing and service area. In addition the concept of TOPSIS has also been connected to multi-objective decision making and group decision making. The Technique for Order of Preference by Similarity to Ideal Solution (TOPSIS) is a multi-criteria decision analysis method which was originally developed by Hwang \& loon in 1981 with further developments by Yoon in 1987 and Hwang, Lai and Liu in 1993.TOPSIS is based on the concept that the chosen alternative should have the shortest geometric distance from the positive ideal solution and the longest geometric distance from the negative ideal solution. It is a method of compensatory aggregation that compares a set of alternatives by identifying weights for each criterion, normalizing scores for each criterion and calculating the geometric distance between each alternative and the ideal alternative which is the best score in each criterion. An assumption of TOPSIS is that the criteria are monotonically increasing or decreasing. Normalization is usually required as the parameters or criteria are often of incongruous dimensions in multi-criteria problems.. To simplify the decision making activities, it is suggested an integrated group TOPSIS procedure for solving real-world problems, with the goal of making effective decisions.

An endeavor has been made in this paper to evaluate the performance of various departments in the industry by using Fuzzy TOPSIS process, so that managers can choose the right decision for improvement with confidence. TOPSIS is the best established technique and used by many researchers to model the decision making processes. It is the technique, which evaluates the alternatives with the ideal solution, the alternative which is closest to the positive ideal solution and farthest from the negative ideal solution, will be the best choice. To convert the linguistic 
International Journal of Recent advances in Mechanical Engineering (IJMECH) Vol.4, No.1, February 2015

data of intangible factors into crisp score the 11 point scale has been used.The results of this research paper convert the subjective decision making process into objective. It becomes easier for managers to compare the different departments on the basis of objective values. This will improve lot of planning and strategies which becomes more effective for the industry.

\section{LITERATURE REVIEW}

Benchmarking evaluation has been targeted by many researchers. Sambasivarao et al. (1997) developed a decision support system for evaluation of advanced manufacturing system. Kengpol et al.(2001) applied analytical hierarchy process to select advanced technology by incorporating quantitative (objective) and qualitative (subjective) factors.Yurdakul(2004) also utilized a combination of analytical hierarchy process and goal programming for evaluation of computerintegrated manufacturing technologies. The model used analytical hierarchy process to determine attributes weights in goal programming. The main problem of these methods is that they are based on accurate measurement and crisp evaluation. But, in our routine life, most of the time attribute involves linguistic terms which need to be converted into crisp scores. Perego et al. (1998) presented reviews on the application of FMADM theory to the evaluation of manufacturing system. Proposed FMADM techniques belong to three categories:(1) fuzzy goal methodology, (2) fuzzy linguistic methods, and (3)fuzzy hierarchical models. G.R.Jahanshahloo et.al.,(2006) extend the method to decision-making problems and among multi-criteria models in making complex decisions and multiple attribute models for the most preferable choice. Mohamed F.and Ei-Santawy et.al.,(2012) select and rank consulting firms by suggesting new multi-criteria decision making approach for financial aspects to be optimized. Carlsson and Fulle (2003) introduced a (heuristic) real option rule in a fuzzy setting, where the present values of expected cash flows and expected costs are estimated by trapezoidal fuzzy numbers. Chen et al. (2007) developed a comprehensive but simple methodology to evaluate IT investment in a nuclear power station based on fuzzy risk analysis and real option approach. Frode (2007) used the conceptual real option framework of Dixit and Pindyck (1994) to estimate the value of investment opportunities in the Norwegian hydropower industry. Villani (2008) combined two successful theories, namely real options and game theory, to value the investment opportunity and the value of flexibility as a real option while analyzing the competition with game theory. Collan et al. (2009) presented a new method for real option valuation using fuzzy numbers. Their method considered the dynamic nature of the profitability assessment, that is, the assessment changes when information changes. As cash flows taking place in the future come closer, information changes and uncertainty is reduced. Chrysafis and Papadopoulos (2009) presented an application of a new method of constructing fuzzy estimators for the parameters of a given probability distribution function using statistical data. Wang and Hwang (2007) developed a fuzzy research and development portfolio selection model to hedge against the environmental uncertainties. They applied fuzzy set theory to model uncertain and flexible project information.

Mansour momeni et.al.,(2011)evaluate different maintenance strategies for different equipment in MCDM problem by imprecise judgment of decision makers using TOPSIS for the evaluation of same. Jihong Pang et.al., (2011) presents a systematic decision support approach to solve the optimization design problems of product quality based on quality function deployment (QFD) and TOPSIS. Iraj alavi et.al., (2011) fuzzy AHP and fuzzy TOPSIS methods are proposed for Plant species selection, where the ratings of various alternative under various subjective criteria and the weights of all criteria are represented by fuzzy numbers. Yahia Zare Mehrjerdi ( 2013) introduce a multi attribute decision making model for radio frequency identification system consisting of four main criteria and five alternatives, and second to develop and solve the proposed fuzzy 
TOPSIS problem. By extension of TOPSIS method, an algorithm to determine the most preferable choice among all possible choices, when data is interval, is presented. K. Shahroudi et.al., (2012) present an integrated model and a supporting approach for effective supplier selection decisions and determined optimum order allocation. Therefore, an integrated approach of ANP-TOPSIS is proposed in choosing the best supplier and defined the optimum quantities order among selected supplier by using a mathematical model. Joshua Ignatius et. al., (2012) provides a novel integration and an unbiased method in reaching a transparent decision making outcome for the funding allocation of projects. The differences in implementation between the AHP-fuzzy-TOPSIS and other similar applications are discussed. F.Hosseinzadeh Lotfi et. al., (2007) extend the TOPSIS method for decision-making problems with Fuzzy data.By this extension of TOPSIS method, an algorithm for determining the most preferable choice among all possible choices in the case of fuzzy data is presented. Karsak et al., (2001) proposed an FMADM procedure for evaluating advanced manufacturing system investments. This approach applied fuzzy discounted cash flow analysis and decision-makers linguistic assessments to the economic criterion and strategic criteria respectively. Then mean operators are used to aggregate the triangular fuzzy numbers used in their algorithm. However, the non-financial terms are not considered in their method. These methods seem to be too complex. Therefore,the objective of this study is to measure performance by using Fuzzy TOPSIS, which further improves the evaluation process. Maysam Ashrafzadeh et.al.,(2012) present a multi-criteria decision making approach for warehouse location selection under fuzzy environment. Under many situations, the values of the qualitative criteria are often imprecisely defined for the decision-makers.In this paper, we present a multi-criteria decision making approach for selecting departments under partial information. To overcome this difficulty, fuzzy multi-criteria decision-making methods are proposed. From the literature as shown in table no.1, the following dimensions are taken, which are further used as attributes for our different alternatives departments of industry.

Table 1. Dimensions of departments

\begin{tabular}{|c|c|c|}
\hline Dimensions & Criterion & Definitions \\
\hline \multirow[t]{2}{*}{ Tangibles } & Building layout & Aesthetic, being convenient of the Industry \\
\hline & Equipment & $\begin{array}{l}\text { The availability of machinery in the production } \\
\text { system achieving to Rate }\end{array}$ \\
\hline \multirow[t]{3}{*}{ Responsiveness } & Timeliness & $\begin{array}{l}\text { Ability to provide operations and promised } \\
\text { production \& quality on time }\end{array}$ \\
\hline & Completeness & $\begin{array}{l}\text { The availability of all kind of services perfectness } \\
\text { at time }\end{array}$ \\
\hline & Willingness & $\begin{array}{l}\text { Helping employees willingly \& completing } \\
\text { requirements }\end{array}$ \\
\hline \multirow[t]{4}{*}{ Reliability } & Accuracy & $\begin{array}{l}\text { Accuracy, consistency given information } \\
\text { regarding dimensions, production rate etc }\end{array}$ \\
\hline & Expertise & $\begin{array}{l}\text { Authority of staff providing reliability to } \\
\text { specialized }\end{array}$ \\
\hline & Image & Creating good vision to staff and maintain it \\
\hline & Security & Protection of every type of system data \\
\hline \multirow[t]{3}{*}{ Assurance } & Salary/rewards & Favorable payment at time \& regard with money \\
\hline & Courtesy & $\begin{array}{l}\text { Courtesy of personnel and their ability to inspire } \\
\text { trust and confidence }\end{array}$ \\
\hline & Compensation & $\begin{array}{l}\text { To give guaranty to the employees in case of a } \\
\text { problem }\end{array}$ \\
\hline
\end{tabular}




\begin{tabular}{|l|l|l|}
\hline Empathy & Caring & $\begin{array}{l}\text { Individualized service attention \& understanding } \\
\text { needs of employees }\end{array}$ \\
\cline { 2 - 3 } & Manner & The attitude of personnel in the department setting \\
\cline { 2 - 3 } & Communication & $\begin{array}{l}\text { Transfer of information between personnel and } \\
\text { employees, the degree of interaction level of two- } \\
\text { way communication }\end{array}$ \\
\hline Professionalism & Skill & Competence and performance of staff \\
\cline { 2 - 3 } & Experience & $\begin{array}{l}\text { The accumulation comes into existence step by } \\
\text { step }\end{array}$ \\
\cline { 2 - 3 } & Innovation & $\begin{array}{l}\text { Developing the personnel and hospital services, } \\
\text { by trainings, using new technologies }\end{array}$ \\
\hline
\end{tabular}

\section{METHODOLOGY}

The proposed model will be followed as figure1 for solution of the problem in this paper. The framework consists of several steps which are consisting of definitions, conversions, modeling and analyzing phases.

Firstly, definition phase consist of introduction of Benchmarking where definition given by different authors are viewed and the behavior of paper is also viewed. Through literature, we are able to be identified the attributes in form of success factors which is quite helpful for preparation of questionnaires and general introduction of TOPSIS approach with FUZZY technique.

In second phase, questionnaire sent to departments where data is obtained in scale of 100 and measured by linguistic data about attributes converted to crisp score by using fuzzy numbers. Third phase included modeling of MADM approach i.e.TOPSIS, where data from fuzzy scale are used and further these will be solved by the steps of TOPSIS approach. Next phase is analyzing, which gives output resultant of the solution that make comparison between departments. This will give ranking of alternatives and conclusion for the study. 


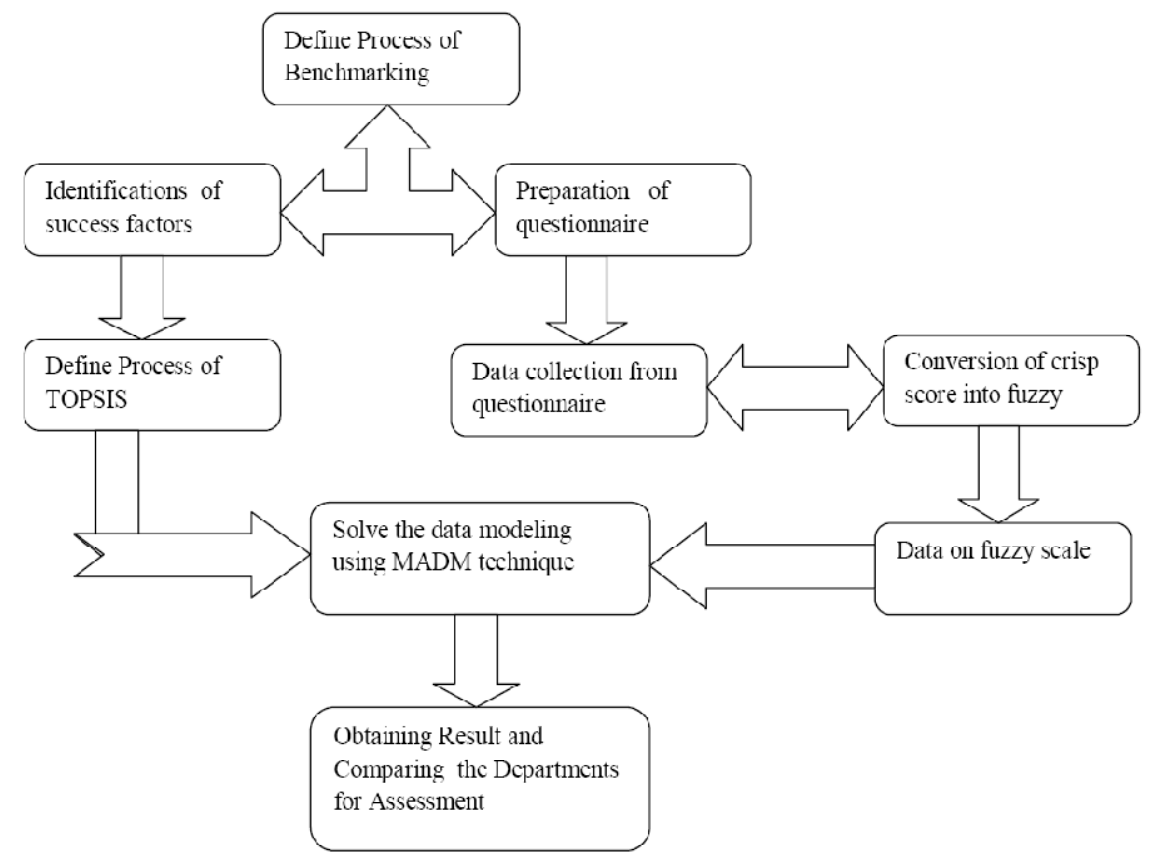

Figure1. Proposed Benchmark model

A brief discussion of Fuzzy Numbers and TOPSIS approach in a fuzzy environment is done in the following sections.

\subsection{FUZZY Numbers}

For converting linguistic terms used for describing intangible factors into crisp score, the evaluation experts use different scales as available in the literature. In this paper, an 11 point fuzzy scale suggested by Chen \& Hwang (1992) has been adopted for measuring performance System. The scale is shown in Table 2.

Table 2 Conversion of Fuzzy Numbers into Crisp Score

\begin{tabular}{|c|c|c|}
\hline Linguistic Terms & Fuzzy Numbers & Crisp Score \\
\hline Exceptionally low & M1 & 0.045 \\
\hline Extremely low & M2 & 0.135 \\
\hline Very low & M3 & 0.255 \\
\hline Low & M4 & 0.335 \\
\hline Below normal & M5 & 0.410 \\
\hline Normal & M6 & 0.500 \\
\hline Above normal & M7 & 0.590 \\
\hline High & M8 & 0.665 \\
\hline Very High & M9 & 0.745 \\
\hline Extremely High & M10 & 0.865 \\
\hline Exceptionally High & M11 & 0.955 \\
\hline
\end{tabular}




\subsection{TOPSIS}

This method was proposed by Hwang \& Yoon (1981) and used to determine the best alternative based on the compromise solution. The compromise solution can be termed as the solution with the smallest Euclidean distance from the positive ideal solution and the farthest distance from the negative ideal solution. The positive ideal solution is regarded as the solution, when all the attributes reach its maximum value, and the negative ideal solution is termed as the solution, when all its attributes reach the minimum level. Therefore, TOPSIS method not only gives the solution closest to the optimal, but farthest from the inferior. The step by step procedure to calculate the best alternative by using TOPSIS method is as described:

Step 1: Building of decision matrix

The first step is to define the problem in terms of alternatives and attributes. This information is expressed in the form of decision matrix, as follows:

$A_{1}, A_{2}, \ldots \ldots \ldots, A_{m}$ represent the set of alternatives; $a_{1}, a_{2}, \ldots \ldots ., a_{n}$ represent the set of attributes; $\mathrm{x}_{\mathrm{ij}}$ represents the values of attributes $j$ for alternative $i$.

$A=\begin{gathered}\text { Alternatives } \\ A_{1} \\ A_{2} \\ \vdots \\ A_{n}\end{gathered}\left[\begin{array}{lllll}x_{11} & x_{2} & \cdots & a_{n} \\ x_{21} & x_{22} & \ldots & x_{2 n} \\ \vdots & \vdots & \ldots & \vdots \\ x_{m 1} & x_{m 2} & \ldots & x_{n n}\end{array}\right]$

Step 2: Formation of normalized matrix

The next step is to form the normalized matrix from the decision matrix, 'A'. Normalization is done to bring the values, in a particular range and moreover, to make them dimensionless. The elements of the normalization matrix, 'B' are calculated as:

$$
n_{i j}=\frac{x_{i j}}{\sum_{i=1}^{m} x^{2}{ }_{i j}}
$$

Where, $\mathrm{x}_{\mathrm{ij}}$ are the elements of the decision matrix, 'A'.

Step 3: Formation of relative importance matrix, 'C'

Experts or practitioners are asked to do pairwise comparison among the attributes. Based upon that a relative importance matrix ' $\mathrm{C}$ ' is formed, which is $\mathrm{n} \mathrm{X} \mathrm{n}$ matrix. This matrix has elements $c_{i j}$ representing the relative importance of the $i$ th attribute over the $j$ th. The diagonal elements of this matrix will be ' 1 '. The symmetric terms of the matrix will be reciprocal of each other. 
Step 4: Calculation of weight vector

Eigenvector method is used to calculate the weight vector, as it allows some inconsistencies arising because of human behavior in building relative importance matrix ' $C$ '. The other approaches can also be applied to find the weights like AHP, ANP, Standard Deviation Method, Entropy Method etc. To find the weight vector by using eigenvector method, the following equation is used:

$\mathrm{Cx}=\lambda \mathrm{x}$

where, $\lambda$ is the eigenvalue of $\mathrm{C}$ and $\mathrm{x}$ is the corresponding eigenvector

The weight vector is calculated as follows:

1) Find $x_{\max }$, eigenvector, corresponding to the maximum eigenvalue $\lambda_{\max }$

2) Find the sum of the elements of $x_{\max }$ as:

$$
\delta=\sum_{i=1}^{n}\left(x_{i}\right)_{\max }
$$

3) Finally, the weight vector is calculated as follows:

$$
w=\frac{\left(x_{\max }\right)}{\delta} \text { such that } \sum_{i=1}^{n} w_{i}=1
$$

Step 5: Formation of weighted normalized matrix

The matrix, which combines the relative weights and normalized specification of the alternatives, is weighted normalized matrix, 'E'.

Step 6: Ranking of alternatives

The weighted normalized matrix ' $\mathrm{E}$ ' is used to find the positive and negative ideal solutions. The Euclidean distance from the positive and negative ideal solution is calculated as:

The Euclidean distance from the positive ideal solution is given as:

$$
S_{i}^{+}=\sqrt{\sum_{j=1}^{m}\left(e_{i}^{+}-e_{i j}\right)^{2}} ; i=1,2,3 \ldots \ldots \ldots \ldots \ldots . . n
$$

The Euclidean distance from the negative ideal solution is given as:

$$
S_{i}^{-}=\sqrt{\sum_{j=1}^{m}\left(e_{i j}-e_{i}^{-}\right)^{2}} ; i=1,2,3 \ldots \ldots \ldots \ldots \ldots . . n
$$

Relative closeness $\left(\mathrm{K}^{*}\right)$ of the Euclidean distance from the positive ideal solution is given as

$$
K^{*}=\frac{S_{i}^{-}}{S_{i}^{-}+S_{i}^{+}}
$$


To select the fuzzy based measurement the performance of departments, a hypothetical example consisting of four alternatives with 6 attributes have been considered, this is shown in the Table 3

Table 3 Data for Measuring Performance

\begin{tabular}{|l|l|l|l|l|l|l|}
\hline Alternatives & AS & EA & RA & PO & RP & TG \\
\hline A & 38 & 63 & 40 & EH & EH & H \\
\hline B & 31 & 62 & 31 & EH & EH & VH \\
\hline C & 50 & 42 & 29 & VH & VH & EH \\
\hline D & 64 & 50 & 52 & H & VH & AN \\
\hline
\end{tabular}

Where, $\mathrm{AS}=$ Assurance, $\mathrm{EA}=$ Empathy, $\mathrm{RA}=$ Reliability, $\mathrm{PO}=$ Professionalism, $\mathrm{RP}=$ Responsiveness, TG= Tangibles, EH=Extremely High, H=High, VH=Very High, AN=Above Normal, $\mathrm{N}=$ Normal

Based upon Table 2, all the values of Table 3, have been converted on the 11 point scale. Linguistic terms are directly derived from the Table 2, like the values of Professionalism, Responsiveness and Reliability. The values of the other attributes have also converted on the Fuzzy scale by using following Equation

$$
y-y_{1}=\underset{\left(\mathbf{x}_{2}-\mathbf{x}_{1}\right)}{\mathbf{y}_{2} \mathbf{y}_{1-}}\left(x-x_{1}\right)
$$

Where, 'y' represents the Fuzzy values of Table 2.

' $\mathrm{x}$ ' represents the objective values of attributes (RO,RP and TG) of Table 3.

Table 4 Data on '11' Point Fuzzy Scale

\begin{tabular}{|c|c|c|c|c|c|c|}
\hline Alternatives & AS & EA & RA & PO & RP & TG \\
\hline A & 0.222 & 0.558 & 0.403 & 0.865 & 0.865 & 0.665 \\
\hline B & 0.045 & 0.533 & 0.110 & 0.865 & 0.865 & 0.745 \\
\hline C & 0.526 & 0.045 & 0.045 & 0.745 & 0.745 & 0.865 \\
\hline D & 0.880 & 0.233 & 0.793 & 0.665 & 0.745 & 0.590 \\
\hline
\end{tabular}

The alternative with the highest relative closeness will be the best choice.In this paper the authors selected the four different departments (A- Human Resources, B- Production, C- Quality Assurance, D- Finance) of a industry in India for applying the TOPSIS approach for priority wise ranking of above departments.

After that develop and distribute the Performa to the different people of Top, Middle and Lower level management of different department of industry for giving the points out of 100.A brief discussion of Fuzzy Numbers and TOPSIS approach in a fuzzy environment is done in the following sections. 
To find the relative importance among the attributes, a group of experts were consulted. The relative importance matrix ' $R$ ' is shown table 5 below.

Table 5 Relative Matrix

$R=$\begin{tabular}{|l|l|l|l|l|l|}
\hline 1 & 0.6 & 0.2 & 0,3 & 0.66 & 0.55 \\
\hline 0.4 & 1 & 0.4 & 0.4 & 0.6 & 0.5 \\
\hline 0.8 & 0.6 & 1 & 0.5 & 0.7 & 0.75 \\
\hline 0.7 & 0.6 & 0.5 & 1 & 0.35 & 0.8 \\
\hline
\end{tabular}

As a next step, maximum Eigen value of the relative importance matrix has been calculated, which is shown below table 6 .

Table 6 Eigen value relative importance matrix

\begin{tabular}{|c|c|c|c|c|c|c|}
\hline \multirow{4}{*}{$\left(\mathrm{R}-\mathrm{J}_{\max } \mathrm{i}\right)=$} & -2.358 & 0.6 & 0.2 & 0,3 & 0.66 & 0.55 \\
\hline & 0.4 & -2.358 & 0.4 & 0.4 & 0.6 & 0.5 \\
\hline & 0.8 & 0.6 & -2.358 & 0.5 & 0.7 & 0.75 \\
\hline & 0.7 & 0.6 & 0.5 & -2.358 & 0.35 & 0.8 \\
\hline
\end{tabular}

In the next step, weights of each attribute are calculated from the knowledge of maximum Eigen value calculated in the previous step and value of weights are $\mathrm{w}_{1}=0.15133$; $\mathrm{w}_{2}=0.15871 ; \mathrm{w}_{3}=0.21678 ; \mathrm{w}_{4}=0.2159$.

In the following step, weight matrix ' $E$ ' is calculated by using Table 7.

Table no.7 Weighted Matrix

$\mathrm{E}=$\begin{tabular}{|l|l|l|l|l|l|}
\hline 0.034 & 0089 & 0.087 & 0.187 & 0.104 & 0.091 \\
\cline { 2 - 6 } & & & & & \\
\hline 0.007 & 0.085 & 0.024 & 0.187 & 0.104 & 0.102 \\
\hline 0.133 & 0.007 & 0.01 & 0.161 & 0.09 & 0.118 \\
\hline
\end{tabular}

This weighted matrix ' $E$ ' is all-inclusive matrix, which takes care of the attribute values and their relative importance. The weighted attributes for performance measurement can be obtained as

\begin{tabular}{|c|c|c|c|c|c|c|c|}
\hline \multirow{2}{*}{$\begin{array}{l}\text { Emax }= \\
\text { Emin }=\end{array}$} & 0.133 & 0.089 & \multicolumn{2}{|c|}{0.172} & 0.187 & 0.104 & 0.118 \\
\hline & 0.007 & 0.007 & \multicolumn{2}{|c|}{0.01} & 0.144 & 0.09 & 0.081 \\
\hline & & \multirow{2}{*}{$\begin{array}{l}\mathrm{Si}^{+}= \\
\mathrm{Si}^{-}=\end{array}$} & 0.18 & 0.24 & \multicolumn{2}{|c|}{\begin{tabular}{l|l|}
0.25 & 0.13 \\
\end{tabular}} & \\
\hline & & & 0.15 & 0.12 & 0.11 & 0.21 & \\
\hline
\end{tabular}

Relative closeness to the ideal solution and ranking of departments based upon performance by using Fuzzy TOPSIS approach. The comparative evaluation by using other technique is beyond the scope of this paper due to its extended length. However, results as obtained from alternative 
reliable and robust technique for the same input criteria have also been shown in Table 8 for comparison.

Table 8 Relative Closeness to Ideal Solution and Ranking

\begin{tabular}{|c|c|c|}
\hline S.No. & $\mathbf{K}_{\mathbf{i}}$ & $\begin{array}{c}\text { Ranking } \\
\text { based on } \\
\text { current } \\
\text { approach }\end{array}$ \\
\hline 1 & 0.46 & $\mathbf{2}$ \\
\hline 2 & 0.34 & $\mathbf{3}$ \\
\hline 3 & 0.30 & $\mathbf{4}$ \\
\hline 4 & 0.62 & $\mathbf{1}$ \\
\hline
\end{tabular}

Table 9.Ranking of departments

\begin{tabular}{|l|l|l|l|l|}
\hline Value & 0,62 & 0.46 & 0.34 & 0.30 \\
\hline Ranking & 1 & 2 & 3 & 4 \\
\hline Department & D (Finance) & A (HR) & B (Production) & C (QA) \\
\hline
\end{tabular}

\section{CONCLUSION}

This paper presents ranking procedure based on performance measurement by using Fuzzy TOPSIS approach. It finds the relative importance among the selected attributes without which inter alternatives comparison is not possible. It presents the subjective decision making problem in terms of merit value, which can be used to evaluate the internal assessment of the company in order for development competitiveness between departments. The proposed technique, takes into account the subjective and objective attributes based on their crisp and linguistic features. This paper will provide ideal benchmark solution using elimination search procedures based on TOPSIS Approach. It finds the relative importance among the selected departments without which inter attribute comparison is not possible. It presents the subjective decision making problem in terms of merit value, which can be used to evaluate the priorities-wise ranking of the internal departments of the XYZ company. The present approach is quite helpful in developing solution strategies to complex manufacturing system behaviors in an easy manner in comparison to other similar techniques as available in the literature. The proposed method can be used as benchmarking for other departments as well as other industries. In future studies, other multicriteria methods should also be considered for evaluating the performance in service industries also.

\section{ACKNOWLEDGEMENT}

I would like to give my special thanks to editors for giving such a wonderful platform of opportunity for researcher to develop their research and also want to give thanks for whole WSP team of publication including everyone from bottom to top management for their corporation. I will be happy for obtaining valuable comments by the editor and reviewers. 
International Journal of Recent advances in Mechanical Engineering (IJMECH) Vol.4, No.1, February 2015

\section{REFERENCES}

[1] G.R.Jahanshahloo , F.Hosseinzadeh Lotfi,M. Izadikhah,(2006)“Extension of the TOPSIS method for decision-making problems with fuzzy data", Applied Mathematics and Computation 181,pp.15441551

[2] C.M. McDermott and G.N.Stock,(1999)"Organisational Culture and Advanced Manufacturing Implementation", Journal of Operation Management, vol. 17, no. 5, pp. 521-533.

[3] Mansour momeni, mohammad reza fathi, mohammad karimi zarchi, sirous azizollahi, (2011) "A Fuzzy

TOPSIS-Based Approach to Maintenance Strategy Selection: A Case Study”, Middle-East Journal of ScientificResearch Vol 8,No.3, pp 699-706

[4] V. P. Agrawal, V. Kohli, and S. Gupta, (1991)"Computer Aided Robot Selection: the Multi Attribute Decision Making Approach", International Journal of Production Research, vol. 29, no. 8, pp. 16241644

[5] K.V. Sambasivarao and S.G. Deshmukh,(1997) "A Decision Support System for Selection and Justification of Advanced Manufacturing Technologies", Production Planning and Control, vol. 8, no.3, pp.270-284.

[6] R.P. Mohanty and S.G. Deshmukh,(2000). "Advanced Manufacturing Technology Selection: A Strategic Model for Learning and Evaluation", International Journal of Production Economics, vol. 55, no. 3, pp. 295-307

[7] Zoran Markovic, (2010) "Modification of TOPSIS Method for Solving of Multi-criteria tasks", Yugoslav Journal of Operations Research Vol 20 No.1, pp.117-143

[8] A. Kengpol and C. O'Brien, (2001)"The Development of a Decision Support Tool for the Selection of Advanced Technology to Achieve Rapid Product Development", International Journal of Production Economics, vol. 69, no. 2, pp. 177-191

[9] M. Yurdakul,(2004)"Selection of Computer-Integrated Manufacturing Technologies using a Combined Analysis Hierarchy Process and Goal Programming Model", Robotics and Computer Integrated Manufacturing, vol. 20, no. 4, pp. 329-340

[10] A. Perego and A. Rangone, "A Reference Framework for the Application of MADM Fuzzy Techniques for Selecting AMTS," International Journal of Production Research, vol. 36, no. 2, pp. 437-458, 1998.

[11] E.E. Karsak and E. Tolga, (2001) "Fuzzy Multi-Criteria Decision Making Procedure for Evaluating Advanced Manufacturing System Investments", International Journal of Production Economics, vol. 69, no. 1, pp. 49-64

[12] M. Salehi and R. Tavakkoli-Moghaddam,(2008)"Project Selection by Using a Fuzzy TOPSIS Technique", World Academy of Science, Engineering \& Technology, vol. 40, pp. 85-90

[13] P. Jain and M. Jain, (2011)"Fuzzy TOPSIS Method in Job Sequencing Problems on Machines of Unequal Efficiencies", Canadian Journal on Computing in Mathematics, Natural Sciences, Engineering and Medicine, vol. 2, no. 6, pp. 155-157

[14] S. Uyun and I. Riadi, (2011) "A Fuzzy Topsis Multiple-Attribute Decision Making for Scholarship Selection", TELKOMNIKA, vol. 9, no.1, pp.37-46

[15] Mohamed F.EI-Santawy, A.N.Ahmed, (2012), “An information entropy weighted method combined to TOPSIS approach for ranking consulting firms", Life science journal,vol 9(1s)

[16] Serafim Opricovic , Gwo-Hshiung Tzeng,(2004)“Compromise solution by MCDM methods: A comparative analysis of VIKOR and TOPSIS”, European Journal of Operational Research vol 156, pp.445-455

[17] Vijay manikrao athawale, shankar chakraborty, "A TOPSIS Method-based Approach to Machine ToolSelection", Proceedings of the 2010 International Conference on Industrial Engineering and Operations Management Dhaka, Bangladesh, January 9 - 10, 2010

[18] Maysam Ashrafzadeh, Farimah Mokhatab Rafiei, Naser Mollaverdi Isfaha, Zahra Zare, (2012) "Application of fuzzy TOPSIS method for the selection of Warehouse Location: A Case Study", Interdisciplinary Journal of Contemporary Reseach in Business January vol 3, no 9 
[19] Jihong Pang, Genbao Zhang, Guohua Chen,(2011)“Application of aggregate analysis for product design quality using QFD model and TOPSIS”, Mechanika, Vol 17,No.6,pp.661-664

[20] Iraj alavi and Hamid Alinejad-Rokny, (2011)"Comparison of Fuzzy AHP and Fuzzy TOPSIS Methods for Plant Species Selection (Case study: Reclamation Plan of Sungun Copper Mine; Iran)", Australian Journal of Basic and Applied Sciences, Vol 5, No.12,pp.1104-1113

[21] Shofwatul 'Uyun, Imam Riadi,(2011) "A Fuzzy Topsis Multiple-Attribute Decision Making for Scholarship Selection”,TELKOMNIKA, Vol.9, No.1,pp.37 46

[22] O. Jadidi, T.S. Hong, F. Firouzi, R.M. Yusuff, N. Zulkifli, (2008) "TOPSIS and fuzzy multi-objective model integration for supplier selection problem", Journal of Achievements in materials and Manufacturing Engineering, Vol 3,No.2

[23] Mir. B. Aryanezhad, M.J. Tarokh, M.N. Mokhtarian \& F. Zaheri,(2011) "A Fuzzy TOPSIS Method Based on Left and Right Scores", International Journal of Industrial Engineering and Production, Vol 22 No 1 pp. 51-62

[24] JiangJiang, Yu-wang Chen, Ying-wu Chen , Ke-wei Yang, (2011) "TOPSIS with fuzzy belief structure for group belief multiple criteria decision making", Expert System with Application,Vol 38,pp.9400-9406

[25] K. Shahroudi, H. Rouydel,(2012) "Using a multi-criteria decision making approach (ANP-TOPSIS) to evaluate suppliers in Iran's auto industry", International Journal of Applied Operation Research, Vol. 2 No 2, pp. 37-48

[26] Emad Roghaniana, Abbas Sheykhanb and Ehsan Sayyad Abendankashib , (2014) "An application of fuzzy TOPSIS to improve the process of supply chain management in the food industries: A case study of protein products manufacturing company, Decision Science Letters, Vol 3,pp. 17-26

[27] Mohammad Reza Mehregan, Mahmoud Dehghan Nayeri, Vahid Reza Ghezavati, (2010),"An optimisational model ofbenchmarking", Benchmarking: An International Journal, Vol. 17 No: 6 pp. $876-888$

\section{AUTHORS}

Bhupender Singh is Assistant Professor in Mechanical Engg. Department at YMCA University of Science and Technology,Faridabad,Haryana, India. He is having 7 yrs experience including Industry \& Teaching. He had guided many students project at masters and bachelor level. He is currently doing research on Benchmarking processes. He had published many research papers in various reputed journals and attending many International \& National Conferences. His area of interest Benchmarking, Industrial Engg,, Quality Managment and Automobiles,

Dr. Sandeep Grover is senior Professor in Mechanical Engg. Department at YMCA University of Science and Technology, Faridabad, Haryana, India. He is presently Registrar and Dean of faculty (Engg. \& Technology)of University. He is having 30 years of experience in teaching and industries. He had guided 08 PHD students for completion their work and Numerous are under process. He is member of various bodies of Govt. of India, University Grant Comission, Department of Science \&

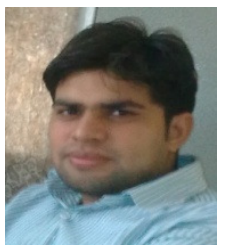
Technology and various universities etc. His area of interest is Total Quality Management, Operation Research, Project Management, Reliabilty, Industrial Engg., MADM approaches etc. He is reviewer of many Journals and chairs of many Conferences at International level. His publications are more than hundreds in very high repute Journals of various publishers.

Dr.Vikram Singh is Associate Professor in Mechanical Engg. Department at YMCA University of Science and Technology, Faridabad,Haryana,India. He is presently Training and Placement Officer of this university also. He is having 15 years of experience at various levels and guided many students of Phd scholars. He had published many research papers in very repute Journals and also reviewers of various Journals. He is also member of various governing bodies of universities. His research area is Project Management,

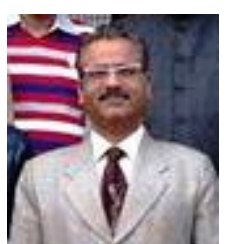
Service Areas, Quality Management and Industrial Engg. 